\title{
Possible Effects of Growth Hormone Therapy on the Eye
}

\author{
AHMED FAWZY, M.Sc.*; NORA EL-SAID BADAWI, M.D.*; MOHAMED M. ISMAIL, M.D.* and \\ MOATAZ HAMED OSMAN, M.D.** \\ The Departments of Pediatrics* and Ophthalmology**, Faculty of Medicine, Cairo University
}

\begin{abstract}
Background: Human growth hormone therapy in children may affect the eye due to its growth promoting properties.

Aim of the Study: To detect possible effects of growth hormone therapy on ocular axial length, refraction and posterior segment.

Patients and Methods: This study included 30 Growth Hormone $(\mathrm{GH})$ deficient children scheduled for human GH therapy. Before GH treatment patients ocular examination included: Dilated fundus, cycloplegic spherical equivalent and axial length using A-scan ultra sound. All the previous examination items were repeated and documented 6 months after treatment start.
\end{abstract}

Results: $30 \mathrm{GH}$ deficient children were included; 17 $(56.7 \%)$ males and $13(43.3 \%)$ females of whom 3 had turner syndrome. Mean age was $11.39 \pm 3.64$ years. Mean spherical equivalent of cycloplegic refraction was $+0.81,0.85$ diopter pre-therapy and $+0.26_{-3} 0.6$ diopter 6 months after therapy $(p-$ value $=0.2$ ). Mean axial length was $21.04_{-3} 1.33 \mathrm{~mm}$ pre-therapy and $21.421 .39 \mathrm{~mm} 6$ months after therapy $(p$-value $=0.12)$. Right sided papilledema occurred in 1 patient with turner syndrome $(1.66 \%) 6$ months after therapy, while no other retinal complications were found.

Conclusion: We found no significant change in ocular axial length and refraction 6 months after GH therapy. One case of pseudotumour cerebri was documented. We recommend routine fundus examination for patients receiving $\mathrm{GH}$ therapy and stop of therapy once papilloedema encountered.

Key Words: Growth hormone - Papilloedema-Axial length - Cycloplegic refraction-Pseudotumour cerebri.

\section{Introduction}

HUMAN Growth Hormone (hGH) therapy in children may affect the eye due to its growth promoting properties [1]. Although well-timed hGh replacement therapy is important for normal emmetropization process, many ocular adverse effects have been reported including papilledema, retinal changes similar to diabetic retinopathy and refractive

Correspondence to: Dr. Ahmed Fawzy, The Department of Pediatrics, Faculty of Medicine, Cairo University changes due to increase in the axial length of the eye [1-4]

The aim of this study is to detect possible changes in ocular axial length and refraction and incidence of posterior segment complications induced by human growth hormone therapy.

\section{Patients and Methods}

This is a prospective interventional study that was approved by the Institutional Review Board and was conducted in compliance with principles of Helsinki declaration. Informed consent was obtained from one of parents of all patients before being enrolled in this study. This study included 30GH deficient children children diagnosed in the Diabetic Endocrine Metabolic Pediatric Unit (DEMPU); Cairo University Children's Hospital and scheduled for hGH therapy in the 6 th October School Health Insurance Hospital during the period between December 2014 and September 2015. All patients recruited in this work were above age of 8 years and had either isolated growth hormone deficiency or Turner syndrome with height below -2SD. The following conditions were excluded: Other endocrinal disorders affecting growth e.g. thyroid hormone deficiency and diabetes mellitus, patients with history of previous GH therapy and ocular disorders that may affect the axial length including: Errors of refraction (myopia $>-3$ diopter and hypermetropia $>+3$ diopter), congenital glaucoma, and micropthalmos.

\section{Baseline data:}

Before start of treatment, relevant medical history was documented for all patients including: Detailed prenatal, natal and postnatal history, consanguinity, family history of short stature, history of medical illness, drug intake and surgery. General examination was done to detect signs of chronic medical illness and genetic abnormalities. 
We also documented pubertal stage and auxological data including: Height Standard Deviation Score (SDS), weight SDS and Mid Parenteral Height (MPH) SDS. Patient ocular examination included: Dilated fundus examination using indirect ophthalmoscope and 20 diopter fundus lens to exclude any retinal or optic disc abnormalities. Cycloplegic refraction was done using autorefractometer (Topcon, Tokyo, Japan) 15 minutes after cyclopentolate eye drops application for 3 times with 5 minutes apart. Axial length was measured using A-scan ultra sound (Sonomed microscan model 100A+, EC21, Indonesia).

\section{GH therapy:}

hGH therapy was given in a dose of $0.03 \mathrm{mg} /$ $\mathrm{kg} /$ day for isolated growth hormone deficiency patients and $0.046 \mathrm{mg} / \mathrm{kg} / \mathrm{day}$ for Turner syndrome for 6 months duration.

\section{Post-therapy examination:}

6 months after treatment start we documented spherical equivalent of cycloplegic refraction and ocular axial length. Dilated fundus examination was done to detect papilledaema (psedotumour cerebri) and retinopathy; including nonproliferative retinopathy, macular edema or neovascularization.

\section{Statistical analysis:}

Data were described in terms of mean \pm Standard Deviation (SD), range or frequencies (number of cases), and percentages when appropriate. Shapiro-Wilk test showed non-normal distribution of data; thus, non-parametric methods were used. Comparison of numerical variables between the study groups was done using Wilcoxon test for dependent samples. A probability value ( $p$-value) less than 0.05 was considered statistically significant. Calculations were done using SPSS (Statistical Package for the Social Science; SPSS Inc., Chicago, IL, USA) Version 17 for Windows.

\section{Results}

\section{Demographic and auxological data:}

$30 \mathrm{GH}$ deficient children were included; 17 $(56.7 \%)$ were males and $13(43.3 \%)$ were females. Mean age was $11.39 \pm 3.64$ years with a minimum age of 8 years and a maximum age of 17 years. Regarding pubertal stage; 22 patients were at stage 1,3 patients were at stage 2, 4 patients were at stage 3 and 1 patient was at stage 4 . According to diagnosis; enrolled cases were 27 isolated GH deficiency patients (90\%) and 3 Turner syndrome patients $(10 \%)$. Mean height SDS of patients was $-4.75 \pm 1$ with a minimum of -8 and a maximum of 3. The mean baseline height SDS of patients with isolated GH deficiency was $-4.62( \pm 1)$ with a minimum of -8 and a maximum of -3 . Six months after therapy, it increased to $-4.40( \pm 1.04)$ with a minimum of -8 and a maximum of -2.8 . The mean baseline height SDS of patients with Turner syndrome was $-4.10( \pm 0.95)$ with a minimum of -5.2 and a maximum of -3.5 . Six months after therapy, it increased to $-3.90( \pm 0.95)$ with a minimum of -5 and a maximum of -3.3 . Mean MPH SDS of patients was $0.32 \pm 1.51$ with a minimum of -2.5 and a maximum of 2.4. Positive consanguinity was found in 6 patients (20\%).

\section{Eye parameters before and after therapy:}

Mean spherical equivalent of cycloplegic refraction was $+0.81 \pm 0.85$ diopters and $+0.26 \pm 0.6$ diopters pre-therapy and 6 months afterwards; respectively ( $p$-value $=0.2)$. Mean axial length was $21.04 \pm 1.33 \mathrm{~mm}$ and $21.42 \pm 1.39 \mathrm{~mm}$ pre-therapy and 6 months afterwards; respectively $(p$-value $=$ 0.12 ). Right sided papilledema occurred in 1 patient (1.66\%) 6 months after therapy, while no other retinal complications were found.

\section{Discussion}

The newborn's eyeball average axial length is about 16 millimeters. Most of axial length elongation occurs in the first 3 to 6 months of life and then slower growth continues over the next two years. The adult size is nearly reached by the age of 3 years and the final adult axial length is reached by the age of 13 . The mean adult value for axial length ranges from 22 to $25 \mathrm{~mm}$ and the mean adult refractive power ranges from -25.0 to $+1.0 \mathrm{D}$. Axial length in adults dose not change with time [5-9] Accordingly, we included patients above age of 8 in which most of the axial length growth has already occurred to detect the effect of GH therapy on the axial length and refraction. Axial length is the main determinant factor of refraction which depends on hereditary and environmental factors. Newborns and infants usually have significant refracive errors and emmetropization occurs with growth $[8,10]$ Rooney et al., reported that the average refractive error at birth was +2.32 diopter, which increased by an average of +0.231 diopter until the age of 7 and then decresed by an average of -0.151 diopter yearly [11]

Growth Hormone $(\mathrm{GH})$ is important for postnatal somatic and ocular growth working via the hepatic Insulin-like Growth Factor I (IGF-I) which induces production of scleral extracellular matrix and angiogenesis resulting in ocular growth. GH 
deficiency may be associated with hypoplasia of the optic nerve and reduced retinal vascularization [12].

We found that the mean pretreatment cycloplegic refraction was slightly hypermetrope; $+0.81 \pm$ 0.85 diopter which is consistent with results of other studies done on normal population in the same age group which has nearly reached the adult axial length [11]. Our results differ from those reported by Parentin et al., in children with congenital GHD in whom they found a signifacant hyperopic refractive error due to a shorter axial length as compared to control group which was explained by the importance of growth hormone in the physiological process of emmetropization [12].

This work found no significant change in axial length and refraction 6 months after GH therapy. This is different from results reported by Parentin et al., who reported that the axial length in GHD children receiving GH therapy showed statistically significant increase after 2 years of therapy leading to myopic shift. However, they found more significant reduction of 2 years cycloplegic refraction in the control group as compared to congenital GHD group receiving substitutive therapy. The difference between the two groups was explained by the late beginning of the therapy in GHD children. They concluded that the early start of substitutive therapy could permit a normal emmetropization process [2]. This difference in results may be due to the longer follow-up period.

Many posterior segment adverse effects of GH treatment have been reported including papilloedema (pseudotumor cerebri), retinal changes similar to diabetic retinopathy and neovascularization [1] We found right sided papilloedema in one case (with turner syndrome) but no other retinal complications were observed. In spite of a lack of symptoms of increased intracranial tension such as headache, MRI brain of this patient showed confirmed the diagnosis of pseudotumour cerebri. Many papers reported occurrence of pseudotumor cerebri (idiopathic intra-cranial hypertension) during $\mathrm{GH}$ replacement therapy $[4,13,14]$. Malozowski et al., reported the development of pseudotumor cerebri in 23 patients treated with hGH and three patients with growth hormone resistance treated with insulin-like growth factor-I [13]. This is a serious complication that needs immediate management before irreversible vision affection occurs. Besch et al., reported two prepubescent girls with visual loss due to pseudotumor cerebri after treatment with recombinant human growth hormone for growth failure. This diagnosis was made 3 and 18 months after start of hormone therapy for each girl. Both had no history of headache or nausea [14]. Simiarly, Reeves et al., reported increased incidence of pseudotumor cerebri cases with the onset of use of recombinant human GH. They found close temporal relationship between onset of GH treatment and pseudotumor cerebri and that resolution occurs with discontinuaion of treatment [4]. On the other hand, Urban et al., reported no harmful effect of GH replacement therapy on the retina and optic nerve which was used for mean duration of $3.05 \pm 1.42$ years and $2.45 \pm 2.32$ years in 10 girls with Turner's syndrome aged 12-16 years and 20 patients with isolated GHD aged 718 years, respectively [1]. Discontinuation of GH treatment in our patient was accompanied by complete reversal of all manifestations of psudotumour cerebri within 6 months.

Reduced retinal vascularization was reported in some patients with growth hormone deficiency. So, incresed retinal vascularisation was expected with GH therapy [12]. The presence of GH in the human retina and vitreous fluid suggested that GH may have a role in the pathogenesis of ocular diseases [15] . Besides, IGF-I was proved to be involved in the pathogenesis of diabetic retinopathy [16]. Yüce et al., evaluated neural and vascular retinal morphology in children with isolated growth hormone deficiency. They found significant reduction of number of vascular branching points while, the mean retinal nerve fibre layerthickness, macular thickness and Intraocular Pressure (IOP) were found similar to control subjects. They found no significant changes in the retinal vascularization, other retinal neural parameters and IOP in cases receiving GH therapy [17]. We found no retinal abnormalities in 6 months follow-up examination.

Our study is limited by small sample size and short follow-up period. But we excluded any condition that may affect ocular axial lengh and we included age group at which adult eye size is nearly reached.

\section{Conclusion:}

We found no significant change in ocular axial length and refraction 6 months after GH therapy. One case of pseudotumour cerebri was documented. We recommend routine fundus examination for patients receiving GH therapy even in the absence of symptoms of increased intracranial pressure and immediate discontinuation of GH therapy if papilloedema occurs to prevent irreversible vision loss. 


\section{Declaration of conflicting interests:}

The authors declared no potential conflicts of interest with respect to the research, authorship, and/or publication of this article.

\section{Funding:}

The authors received no financial support for the research, authorship, and/or publication of this article.

\section{References}

1- URBAN B., GARDZIEJCZYK M., URBAN M. and BAKUNOWICZ-LAZARCZYK A.: Effect of human growth hormone treatment on the eyes of patients with somatotropic pituitary insufficiency and in girls with Turner's syndrome. Endokrynol Diabetol Chor Przemiany Materii Wieku Rozw., 11 (1): 9-12, 2005.

2- PARENTIN and PERISSUTTI P.: Congenital growth hormone deficiency and eye refraction: A longitudinal study. Ophthalmologica, 219 (4): 226-31, 2005.

3- CEGARRA M.J., CASANOVA I.J., ALONSO L., HERNANDEZ G.T., RAHHAL M.S., MARTINEZ S.F. and SANCHIS J.A.: Consolidating the anatomical relationship between ocular axial length and spherical equivalent refraction. Eur. J. Anat., 5 (3): 145-50, 2001.

4- G.D. REEVES and D.A. DOYLE: Growth Hormone Treatment and Pseudotumor Cerebri: Coincidence or Close Relationship? J. Pediatr. Endocrinol. Metab., 15 Suppl 2: 723-30, 2002.

5- GOLDSCHMIDT E.: Refraction in the newborn. Acta Ophtahmol. (Copenh), 47: 570-78, 1969.

6- FLEDELIUS H.C.: Ophthalmic changes from age 10 to 18 years. A longitudinal study of sequels of low birth weight. I. Refraction. Acta. Ophthalmol. (Copenh), 58: $889,1980$.

7- FLEDULIUS H.C.: Ophthalmic changes from age 10 to 18 years. A longitudinal study of sequels to low birth weight. III. Ultrasound oculometry and keratometry of anterior eye segment. Acta Ophthalmol. (Copenh), 60: 393, 1982.

8- BHARDWAJ V. and RAJESHBHAI G.P.: Axial length, anterior chamber depth-a study in different age groups and refractive errors. J. Clin. Diagn. Res., 7 (10): 22112, 2013.

9- FULTON A.B., DOBSON V., SALEM D., MAR C., PETERSON R.A. and HANSON R.M.: Cyclopegic refractions in infants and young children. A.M. J. Ophthalmol., 90: 239-47, 1980.

10- MANTYJARVI M.I.: Predicting of myopia progression in school children. J. Pediatr. Ophthalmol. Strabismus, 22: 71-5, 1999.

11- ROONEY J.: Fitting children with glasses. J. Ophthalmic Nurs. Technol., 24 (1): 23-9, 1995.

12- PARENTIN F., TONINI G. and PERISSUTTI P.: Curr. Eye Res., Refractive evaluation in children with growth defect, 28 (1): 5-11, 2004.

13- MALOZOWSKI S., TANNER L.A., WYSOWSKI D.K., FLEMING G.A. and STADEL B.V.: Benign intracranial hypertension in children with growth hormone deficiency treated with growth hormone. J. Pediatr., 126 (6): 9969, 1995.

14- BESCH D., MAKOWSKI C., STEINBORN M.M., BONFIG W. and SADOWSKI B.: Visual loss without headache in children with pseudotumor cerebri and growth hormon etreatment. Neuropediatrics, 44 (4): 203-7, 2013.

15-HARVEY S., PARKER E., MACDONALD I. and SANDERS E.J.: Growth hormone is present in the human retina and vitreous fluid. Neurosci. Lett., 22; 455 (3): 199-202, 2009.

16- POULAKI V., JOUSSEN A.M., MITSIADES N., MITSIADES C.S., ILIAKI E.F. and ADAMIS A.P.: Insulin-like growth factor-I plays a pathogenetic role in diabetic retinopathy. Am. J. Pathol., 165 (2): 457-69, 2004.

17- YÜCE Ö., YALÇıN N.G., BIDECI A., et al.: Retinal neural and vascular structure in isolated growth hormone deficiency children and evaluation of growth hormone treatment effect. J. Clin. Res. Pediatr. Endocrinol., 10 (2): 113-8, 2018.

\section{التأثيرات المحتملة على العين للعلاج بهرمون النمو}

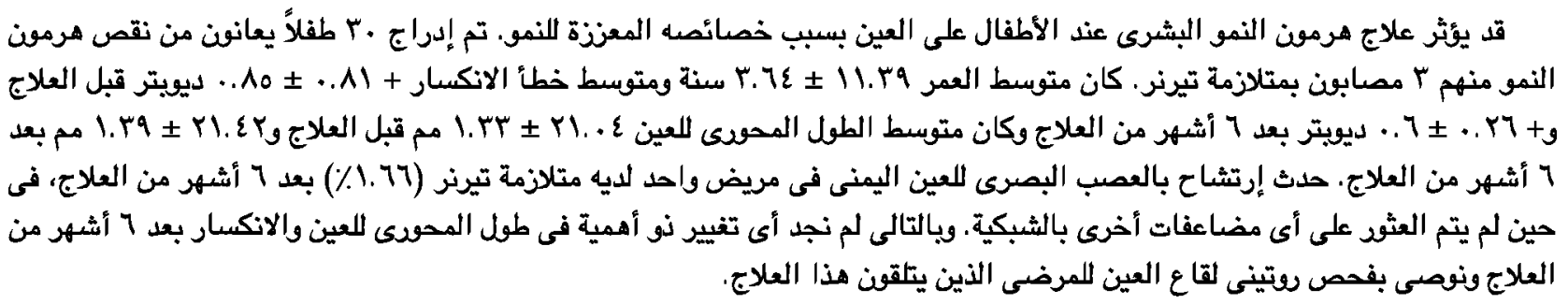

